\title{
PEDRO DE OBREGÓN Y LA MINIATURA TOLEDANA A MEDIADOS DEL SIGLO XVII
}

\author{
Jaime Moraleda Moraleda* \\ Universidad de Castilla-La Mancha \\ jaime.moraleda@uclm.es
}

\begin{abstract}
Resumen
En el siglo xvi la catedral de Toledo mantuvo un constante programa de mecenazgo en relación con el encargo de códices miniados para sus principales funciones litúrgicas. El Misal Rico de Cisneros, que supuso el inicio de la centuria bajo las pautas estéticas de la Escuela de Gante y Brujas, fue abriendo paso a una mayor incorporación de los repertorios all'antica, consolidados en el último cuarto de siglo, entre múltiples variantes del grutesco y novedosas composiciones renacentistas. La centuria del Setecientos se inició con los últimos trabajos para el Misal del Cardenal Quiroga, en el que Juan de Salazar trabajó como iluminador principal, muy influenciado por la corriente manierista imperante; si bien pronto advertimos un progresivo abandono en la producción de manuscritos iluminados, con grandes intervalos de ausencia de trabajos. La documentación consultada, que ha permitido un rastreo minucioso relacionado con esta actividad, revela la presencia del pintor madrileño Pedro de Obregón como uno de los últimos miniaturistas al servicio de la catedral primada, cuya obra, aún poco estudiada, presenta rasgos propios de las pautas estilísticas del Barroco, en un ambiente en el que se vislumbra una progresiva decadencia en el número de encargos relacionados con nuevos proyectos de iluminación.
\end{abstract}

Palabras clave: catedral de Toledo, Pedro de Obregón, manuscrito iluminado, Barroco.

\section{PEDRO DE OBREGÓN AND THE TOLEDANIAN MINIATURISM \\ IN THE MIDDLE OF THE 17TH CENTURY}

\section{Abstract}

Throughout the sixteenth century the Cathedral of Toledo continued its patronage program related to commission of illuminated manuscripts for its liturgical ceremonies. The Missal Rico de Cisneros, which marked the beginning of the century under the aesthetics of the School of Ghent and Bruges, opened the way to the incorporation of the all'antica repertoires developed in the last quarter of the century, under the multiple variants of the grutesco and the new Renaissance compositions. The seventeenth century began with the latest works for the Cardinal Quiroga's Missal, in which Juan de Salazar worked as the main illuminator, influenced by Mannerist aesthetics; although, we soon noticed a lower production of illuminated manuscripts, with large periods without works. The documentary investigation reveals the presence of the painter Pedro de Obregón, born in Madrid, as one of the last miniaturists in the service of the primated cathedral, whose work presents the main characteristics of the Baroque style, as well as a progressive decline of miniature works. Keywords: Cathedral of Toledo, Pedro de Obregón, illuminated manuscript, Baroque. 


\section{INTRODUCCIÓN ${ }^{1}$}

Las décadas finales del siglo Xvi recuperaron el esplendor de los trabajos de miniatura que habían brillado por su calidad y abundancia bajo el mecenazgo de los prelados toledanos (Fernández Collado 1999). La catedral primada, que aún vivía un periodo de notable protagonismo económico entre las principales sedes episcopales españolas, no desatendió la producción miniada, cuyo mejor ejemplo fueron los trabajos de escritura, iluminación y encuadernación para el Misal del Cardenal Quiroga (Moraleda 2018).

Gaspar de Quiroga y Vela, prelado desde 1577 a 1594, fue el último gran mecenas del siglo XVI, sustituido en la cátedra arzobispal por el archiduque Alberto (1594-1595), como se dejó constancia en la reseña de su fallecimiento:

En veinte de noviembre de 1594 murió el Illmo. y Rvmo. S. don Gaspar de Quiroga Cardenal Arzobispo de Toledo el cual en su vida tenía nombrado por coadjutor con futura sucesión en el arzobispado al serenísimo señor cardenal Archiduque Alberto sobrino del rey Phelipe nuestro señor ${ }^{2}$.

Durante su arzobispado hemos podido rastrear todos aquellos nombres vinculados con los trabajos de iluminación de manuscritos, según las cuentas de los libramientos del Archivo de Obra y Fábrica: Gaspar López, Pablo Ruiz, Andrés de Morata, Alonso el Rico, Ambrosio de Salazar, Juan Martínez de los Corrales y Juan de Salazar, si bien fueron los dos últimos los principales artífices de los trabajos de iluminación del citado misal, un conjunto de diez volúmenes ${ }^{3}$ que podemos considerar el principal encargo de producción miniada registrado en los documentos capitulares a finales de la centuria (Moraleda 2018).

Martínez de los Corrales, capellán del coro de la catedral de Toledo, trabajó entre 1580 y 1590 al servicio de cabildo toledano. Entre sus obras destaca la decoración de un epistolario, un capitulario y los dos primeros tomos del Misal de Toledo. Tras su fallecimiento los encargos corrieron a cargo de Juan de Salazar, quien estuvo decorándolo hasta su muerte en 1604, por lo que el manuscrito fue iniciado bajo el mandato del cardenal Gaspar de Quiroga (1577-1594) y concluido a principios del siglo XVII, con Sandoval y Rojas como arzobispo (1599-1618 ${ }^{4}$. Desde el año 1600 los pagos a Salazar no sólo se realizaron en función de las entregas tasadas, sino como asalariado de la Obra, según consta en el registro de libramientos,

${ }^{1}$ Este estudio se enmarca como parte del proyecto de investigación Toledo e Italia. Relaciones artísticas de ida y vuelta (ss. XVI-XVIII), (SBPLY/19/180501/000311), coordinado por la profesora Palma Martínez-Burgos García (Universidad de Castilla-La Mancha).

${ }^{2}$ Archivo Capitular de Toledo (=ACT). Archivo de Obra y Fábrica (=OF) 897, folio 1.

3 Seis volúmenes estaban destinados a la lectura en el lado de la Epístola y los cuatro restantes al lado del Evangelio.

${ }^{4} \mathrm{Al}$ revisar los últimos cuadernos del códice, podemos advertir la presencia de algunos trabajos de miniatura sin concluir, apenas esbozados, lo que pudo verse motivado por la ausencia de relevo artístico tras la muerte de Juan de Salazar. 
de esta manera recibía todos los años dos mil maravedís como iluminador, según interpretamos del siguiente texto capitular: $\mathrm{Ha}$ de aver juan de Salazar iluminador 2000 maravedis de salario en cada año, por tercios.

Nunca antes, ni en los momentos de máxima actividad, se había introducido un gasto anual por tareas de iluminación, como sí había ocurrido en las actividades de pintor, escultor, incluso para oficios menores como el de relojero. Quizá la figura de Juan de Salazar y el arte magistral de su obra hizo necesario un reconocimiento con el que asegurar su compromiso con la catedral, pues en décadas anteriores la itinerancia de miniaturistas entre los principales centros civiles o eclesiásticos fue la norma y no la excepción (Muntada 1992).

Tras el libramiento de 1603, por el que se abonaron a Salazar mil trescientos cuarenta reales, no se volvieron a registrar pagos por estos menesteres hasta 1609 , aunque nunca más a su persona, que de igual manera desaparece de los registros del salario anual. Sin duda hemos de pensar que le sobrevino la muerte a quien fuera uno de los grandes iluminadores del siglo Xvi en Espańa, idea que compartía Ceán Bermúdez (1800):

Salazar (Juan de) iluminador. Trabajó con fray Andrés de León y fray Julián de la Fuente del Saz en los libros del coro del monasterio del Escorial. Concluida esta gran obra pasó a Toledo, y el cabildo de la catedral le encargó el ańo de 1590 siguiese trabajando en un juego de misales, que había principiado en 1583 el clérigo Juan Martínez de los Corrales, del que solo iluminó los dos primeros tomos. Salazar trabajó en los restantes hasta 1604, que falleció en aquella ciudad, dexando la obra por concluir; pero digna de aprecio por la corrección del dibuxo, por la hermosura y limpieza del colorido y por los caprichosos adornos de buen gusto.

La obra del misal quedó inconclusa, lo que se puede apreciar en los trabajos de iluminación de algunos volúmenes, concretamente en los códices Ms. 56.6 y Ms. 56.9 (Janini y Gonzálvez 1977), donde se suceden varios huecos en blanco correspondientes a las letras capitales no iluminadas, o bien simplemente esbozado su ductus con pigmentos planos, fruto de una mano indiscutiblemente inexperta. Estos detalles consolidan la hipótesis de una especialización rigurosa del trabajo de ejecución del códice, donde el amanuense y el miniaturista, así como el encuadernador o el pergaminero, ejercían labores absolutamente independientes.

5 ACT, OF, 1601, fol. 90. 


\section{EL SIGLO XVII Y LA DECADENCIA EN LOS TRABAJOS DE ILUMINACIÓN: LAS FUENTES DOCUMENTALES Y SU INTERPRETACIÓN}

La decoración a través de colores planos y filigrana de tinta en algunas capitales se impuso desde los inicios de la nueva centuria, lo que corría en paralelo a una notable mengua en los encargos de libros manufacturados, multiplicándose la demanda de volúmenes impresos decorados con grabados (Fernández Collado et al. 2009). Incluso en aquellos ejemplares en los que se mantenía la elaboración manual de la escritura y su ornamentación, como fueron los grandes libros de coro para canto llano y polifónico, el despliegue de esmeradas orlas desapareció por completo, concentrándose exclusivamente la producción miniada en algunas de las principales letras de introito. El libro quedó finalmente despojado de su antiguo carácter suntuoso y decorativo, atractivo no sólo por lo que nos contaban las viñetas con historias catequéticas, sino por todo aquello que las envolvía; un elenco de virtuosas fanfarrias militares, grutescos, insectos y flores, monstruos y animales satíricos que sucumbieron con el paso de los años.

Los trabajos con los que se reanudaron las tareas de iluminar no fueron de envergadura, pues recayeron en manos de escribanos, cuya técnica no depurada generó una obra de escaso valor artístico. Así nos encontramos libramientos a favor del escribano Alonso de Morata, quien en 1604 acabó de escribir, apuntar e iluminar el tomo séptimo del Oficio de Tempore, así como los trabajos de letras grandes y mayores yluminadas en un libro intitulado de la açension visperas y maytines ${ }^{6}$ en 1609. Un caso semejante quedó anotado en los libramientos de 1611, cuando el escribano Eugenio de Mezquita recibió la cantidad de seiscientos seis reales y medio por los trabajos de escribir e iluminar en un libro de coro. No podemos afirmar con exactitud en qué volúmenes trabajó Mezquita, pues los datos del libramiento son verdaderamente escasos, si bien se conservan en la Biblioteca Capitular un número importante de salterios en los que aparecen algunas iniciales decoradas que denotan un manejo menos preciso de la técnica artística. La fuente documental de la Obra y Fábrica, aunque sucinta, ha sido de gran utilidad para contextualizar el proceso de declive de una de las más notables manufacturas que se había mantenido con un elevado nivel productivo a lo largo de las anteriores centurias:

En 14 de junio se libró al dicho eugenio de mezquita doscientos y noventa y quatro reales por haber escrito el officio de la Visitacion en dos libros que cada uno contiene treynta ojas veynte letras yluminadas una grande de dos renglones con dibujo y veintiocho quebradas como todo lo çertifica el Racionero Peńa corrector de los libros de canto en su relación que esta junto con la librança ${ }^{7}$.

\footnotetext{
${ }^{6}$ ACT, OF, 1609, Escribir y encuadernar, fol. 155.

7 ACT, OF, 1611, Escribir y encuadernar, fol. 151.
} 
Hemos de esperar a 1653 para encontrar de nuevo referencias documentales relativas a trabajos especializados de iluminación en manuscritos de uso litúrgico, lo que supuso un inmenso vacío temporal que ratifica el deterioro de la actividad y la decadencia de un arte que no volvió a recuperar su pretérito esplendor. Aunque se habían sucedido algunos pagos a Juan Ramírez de Arellano por escribir y reponer hojas en los libros para el coro, así como al librero Francisco García por sus encuadernaciones, no se trataba de profesionales de la miniatura. De igual manera podemos desgranar algunos libramientos por la compra de pieles, tanto para escritura como para encuadernación, pero nada de obras miniadas, ni referencias a miniaturistas. Finalmente, el 26 de octubre de 1653 se anotó el libramiento al pintor Pedro de Obregón, vecino de Madrid, quien recibió seis mil ochocientos maravedís por sus trabajos como iluminador en un salterio que estaba escribiendo Juan Ramírez de Arellano.

Los cambios que se produjeron en el Misal Romano desde 1604 con la Bula Cum sanctissimum Eucharistiae de Clemente VIII, así como los promulgados por Urbano VIII en $1634^{8}$, tuvieron importantes consecuencias que también afectaron a otros volúmenes de función litúrgica, pues los numerosos libros de canto que se habían escrito a los largo de los últimos años del siglo xvi y primeros del siguiente se vieron alterados con la intención de adaptarse a las correcciones, lo que generó el encargo de nuevos códices para el rito (Palacios 2018). En Toledo, los nuevos volúmenes fueron copiados por Juan Ramírez de Arellano, quien los concluyó en 1681, cuyo conjunto lo componen seis pares, aunque sólo los tres primeros se iluminaron con grandes vińetas realizadas por Pedro de Obregón (Ms. Cantoral 12.1A; Ms. Cantoral 12.1B; Ms. Cantoral 12.2A; Ms. Cantoral 12.2B; Ms. Cantoral 12.3A; Ms. Cantoral 12.3B), el resto de letras están decoradas con pigmentos planos y son de sencilla ejecución, por lo que las consideramos obra del escribano:

En 24 de mayo de 1653 ańos se libro a juan ramirez de arellano escritor de libros mill R de vellón que valen 34000 maravedis a quenta del salterio que esta haciendo para la obra conforme la escritura que tiene echa en 19 de febrero del año pasado de 52 y conforme la çertificacion que ba con la libranza?.

En 26 de octubre de 1653 años se libro a Pedro de obregón iluminador 200 reales de vellón que valen 6800 maravedis los quales son a quenta de lo que hubiere de haber por iluminar las letras del salterio que escribe juan ramirez... ${ }^{10}$.

Las notas del libramiento capitular nos sitúan ante la importancia de una escritura pública, previa al desarrollo de la actividad, un compromiso entre el artista y el comitente de notable importancia para poder rastrear las condiciones del acuerdo

${ }^{8}$ Con la Bula Si quid est, del 2 de septiembre de 1634, el pontífice mandó expurgar la edición de 1570 de errores tipográficos, cuya principal consecuencia fue la ejecución de nuevos volúmenes rectificados.

9 ACT, OF, 1653, Escribir y encuadernar, fol. 137.

${ }^{10}$ ACT, OF, 1653, Escribiry encuadernar, fol. 137v. 
entre las partes, así como la independencia o supeditación del miniaturista, y por consecuencia las características de la obra final (Revenga Domínguez 1999). En esta ocasión tenemos la fortuna de acceder al contrato por el cual Pedro de Obregón se obliga a iluminar las letras de un salterio de la Catedral Primada ${ }^{11}$. El interesante documento (Revenga Domínguez 1999), fechado el día 25 de octubre de 1653, presenta a las partes interesadas en el acuerdo; de parte del cliente consta Pedro López de Ynarra, obrero mayor de la catedral de Toledo, mientras que Pedro de Obregón actúa en su nombre como pintor. El texto nos permite rastrear las obligaciones a las que se vincula Obregón con la aceptación del contrato en base a una serie de disposiciones, en las que se resaltaba el uso de buenos colores y de buen oro y plata, la manera del pago, el plazo de entrega, así como la elección iconográfica para cada una de las capitales seleccionadas:

Primera letra duplicada del salmo que enpieça de Dixit Dominus, las a de hacer con su follaje adornada con toda perfeción y con una ystoria en medio de la letra de un David con la cabeça del jigante en una mano y con el montante en la otra. En otra letra duplicada de dilexit quoniam, la bisitación de Nuestra Señora. En otra letra duplicada que dice lietatus sum, la adoración de los reyes. En otra letra duplicada que dice ni si dominus edifica, la huida a Egipto. En otra letra duplicada, memento Domine David, la cena de Cristo con sus discípulos. En otra letra duplicada confitebontibi Domine, la entrada de ramos. En otra letra duplicada benedictus Dominus Deus meus, una Nuestra Señora con su Niño en los braços en pie. En otra letra duplicada cun ynbocaren, el sepulcro de Cristo con abad de Matías. En otra letra duplicada del oficio parvo de Nuestra Señora dixit dominus, una historia de Nuestra Señora ${ }^{12}$.

El siguiente año de 1654 se registró el último de los libramientos por iluminar los salterios del coro, momento en el que se pagaron cuatro mil trescientos reales de vellón, que sumados a los doscientos ya recibidos hacen el montante de cuatro mil quinientos, según consta en el contrato. Tras un balance económico de los costes por los trabajos de iluminación podemos concretar que recibió, por cada letra, la cantidad de doscientos cincuenta reales, lo que supone una tasación muy superior respecto de los pagos por historias que recibía Juan de Salazar, sólo cincuenta años antes. Si tomamos como referencia la historia de santa Águeda, iluminada por Salazar en 1592, recibió por ella doce ducados ${ }^{13}$, que equivalían a ciento treinta y dos reales; incluso en la tasación realizada por Luis de Velasco de una página completa con las armas del arzobispo Sandoval y Rojas, el trabajo fue valorado en doscientos reales $^{14}$, por lo que en ambos casos se constata la notable diferencia.

${ }^{11}$ Archivo Histórico Provincial de Toledo. (=AHPT), prot. 3.153, esc.: Rodrigo de Hoz, fols. 905-908.

12 AHPT, prot. 3.153, esc.: Rodrigo de Hoz, fol. 905.

13 ACT, OF, 893, Escribir y encuadernar, fol. 166v.

14 ACT, OF, 1603, Escribir y encuadernar, fol. 163. 
Las siguientes notas confirman la totalidad del pago por las dieciocho letras iluminadas en los dos primeros volúmenes del cuerpo del salterio (Ms. Cantoral 12.1A; Ms. Cantoral 12.1B), acorde con la escritura pública ante el notario Rodrigo de la Hoz, siendo testigos Juan de Llano, Joan Díaz y Gabriel de Romaní, vecinos en Toledo:

En 27 de mayo de 1654 ańos se libro a Pedro de obregón vecino de Madrid 4300 reales de vellon que valen 146200 maravedis con los quales y otros 200 que tiene recibidos en libranza a quenta en 26 de octubre del año proximo pasado de 53 se le pagan 4500 reales del precio de diez y ocho letras yluminadas que a echo para los salterios a razón de $250 \mathrm{R}$ cada letra conforme la escritura ante $\mathrm{R}^{\circ}$ de la hoz a 25 de octubre de $53^{15}$.

En adelante, sólo volvemos a encontrar referencias por partidas de iluminación en 1658, cuando se dejó constancia de un nuevo trabajo de Obregón, quien recibió la cantidad de dos mil quinientos reales pos sus iluminaciones en un psalterio de horas menores ${ }^{16}$ y que coincide con los trabajos de miniatura encontrados en los dos pares siguientes (Ms. Cantoral 12.2A; Ms. Cantoral 12.2B; Ms. Cantoral 12.3A; Ms. Cantoral 12.3B), con un total de diez letras iluminadas, aunque de esta partida no hemos hallado el contrato previo a la ejecución del libramiento.

Por su parte, el escribano Juan Ramírez de Arellano continuó como copista en los libros del coro, donde intervino decorando en algunas letras, como ha quedado registrado en los pagos de $1681^{17}$. Semejantes notas nos confirman el oficio de escribano y miniaturista de Manuel García Rodríguez en 1686, quien concluyó un nuevo libro para las oraciones de todo el año, en el que se le pagaron dos letras iluminadas, a 12 reales cada una ${ }^{18}$. En consecuencia, y acorde al seguimiento de las fuentes documentales consultadas, podemos confirmar la decadencia y progresivo abandono en el que se vio sumido el arte de la miniatura.

\section{PEDRO DE OBREGÓN: EL SEMBLANTE DE UN PINTOR E ILUMINADOR}

El pintor y grabador Pedro de Obregón nació en Madrid hacia 1597 y murió en la misma ciudad hacia 1670. Fue considerado por Palomino como uno de los mejores discípulos de Vicente Carducho y procuró imitar a su maestro en la corrección del dibuxo y en la fuerza del claro oscuro (Ceán Bermúdez 1800). Entre sus pin-

${ }^{15}$ ACT, OF, 1654, Escribir y encuadernar, fol. 168.

${ }^{16}$ ACT, OF, 1658, Escribir y encuadernar, fol. 159.

17 ACT, OF, 1681, Escribir y encuadernar, fol. 186v.

${ }_{18}$ El menor valor de tasación de estas letras confirma que se ha de tratar de trabajos ornamentales, no tanto de iniciales o viñetas historiadas, tal y como hemos considerado que sería la contribución de los escribanos en la iluminación de los códices. 
turas reconocidas destacan los lienzos de san Joaquín y santa Ana para el retablo de La Concepción de la parroquia madrileña de Santa Cruz, aunque la más renombrada pintura es el óleo que representa la Santísima Trinidad en el convento de la Merced Calzada, en la misma ciudad, todos ellos desaparecidos (Angulo Íńiguez 1983). El convento de Santa Clara de Villacastín (Segovia) conserva de su producción un óleo sobre lienzo con la aparición del Niño Jesús a san Antonio, semejante al que posee el Museo Nacional del Prado, fechado en 1633 y atribuido al mismo autor por Diego Angulo y Alfonso Pérez Sánchez. Observamos aquí, como efecto y herramienta del Barroco, un rompimiento de gloria sobre la figura del santo, donde una corte de ángeles músicos acompaña la imagen mística del Niño, para cuyo diseño Obregón siguió el modelo creado por Vicente Carducho para el mismo episodio místico, obra de 1631 conservada en el Museo del Ermitage (Pérez Sánchez 1992).

De sus trabajos como grabador, Ceán Bermúdez deja constancia en su diccionario (1800) de que posee dos ejemplares: una estampa pequeña donde figura una mujer (sic) sentada pintando y dos genios sosteniendo un pebellón y otra con el pasage de santo Domingo in Soriano, según modelo de un original de Alonso Cano. La Biblioteca Nacional de Madrid conserva un ejemplar de este último, así como otro cuya escena representa la imagen del rey Carlos II y Mariana de Austria, firmado por Obregón y publicado en la Nudrición Real de Pedro González de Salcedo en 1671 (Gallego 1999). La indefinida fecha del fallecimiento de nuestro autor ha generado dudas respecto de la autoría de la última estampa, si bien en mi opinión no es en absoluto descartable, pues, aunque Ceán Bermúdez apunta como fecha del deceso el año de 1659, no hemos encontrado ningún documento que lo pruebe, igual que tampoco existe nada al respecto de la hipótesis de 1669, defendida por otros, por lo que podríamos considerar el citado grabado, por ahora, como una de sus últimas obras.

Cuando Céan Bermúdez hizo referencia a un pintor homónimo en su compendio de artistas (1800), refiriéndose a él como iluminador para la santa iglesia de Toledo en 1564, expuso un dato que consideramos incorrecto, pues en nuestro vaciado documental, relativo a los miniaturistas que trabajaron para la sede episcopal toledana durante todo el siglo XVI, no aparece ninguna referencia con dicho nombre. Más entendemos la nota cronológica como un error tipográfico a la hora de transcribir las fechas, al cambiar 1654 por 1564 , por lo que a nuestro parecer sólo existe un autor con este nombre, cuyos trabajos para la catedral de Toledo quedaron registrados entre 1653 y 1658, como ya hemos dejado constancia de ello a través de las fuentes. El mismo error es recogido por Domínguez Bordona en su Diccionario de iluminadores españoles (1957), quien vuelve a situar a Obregón como miniaturista del siglo xvi. Esto nos llevaría a prescindir del apodo «el Joven" con el que se distingue a Pedro de Obregón, según recoge incluso el catálogo del Museo del Prado.

Las capitales iluminadas por Pedro de Obregón en los salterios de Toledo no coinciden con los repertorios habituales de la Escuela Toledana del primer tercio del siglo XVII, como Tristán, Orrente o Sánchez Cotán, en los que se fraguó un tratamiento tenebrista de la luz. Tampoco pretendió imitar los rasgos de su maestro Vicente Carducho, ni podemos ver en sus diseños las formas habituales de contem- 


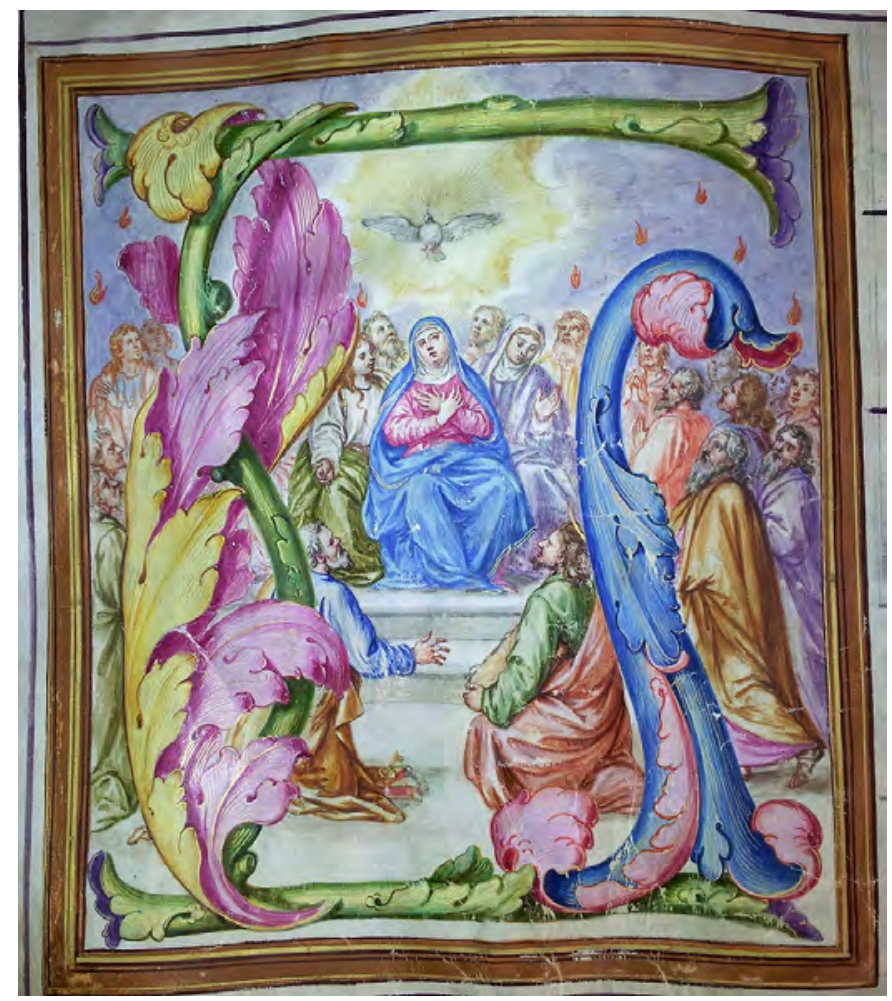

Figura 1. Pentecostés. Salterio de Toledo. Pedro de Obregón, 1654.

Biblioteca Capitular de Toledo.

poráneos como Antonio de Pereda (Urrea 1994). Obregón utilizó en sus miniaturas un estilo clasicista, muy decorativo y algo encorsetado, cuyas pautas conservadoras venían impuestas, en parte, por el condicionante técnico y espacial del objeto a decorar, donde no hay excesivas licencias a complejas composiciones, ni teatrales tratamientos (fig. 1).

El arte eclesiástico adquiere en el Barroco un carácter doctrinal que pierde sus rasgos espontáneos y subjetivos. La Iglesia, consciente de las licencias intelectuales a la hora de plasmar la imagen, pretendió un férreo control, dentro de una esfera lo más ortodoxa posible. El rigor doctrinal parece haber guiado la elección de Obregón en los modelos conservados en los salterios de Toledo, pues todas las escenas evidencian una ortodoxa y rigurosa conexión con los principios tridentinos de instruir en la verdad (González García 2015) (fig. 2).

Los episodios seleccionados para las capitales los hemos encontrado distribuidos en los referidos volúmenes del salterio de la siguiente manera: Ms. Cantoral 12.1A (David con la cabeza de Goliat, fol. 2r; la Epifanía, fol. 38v; la Última Cena, 


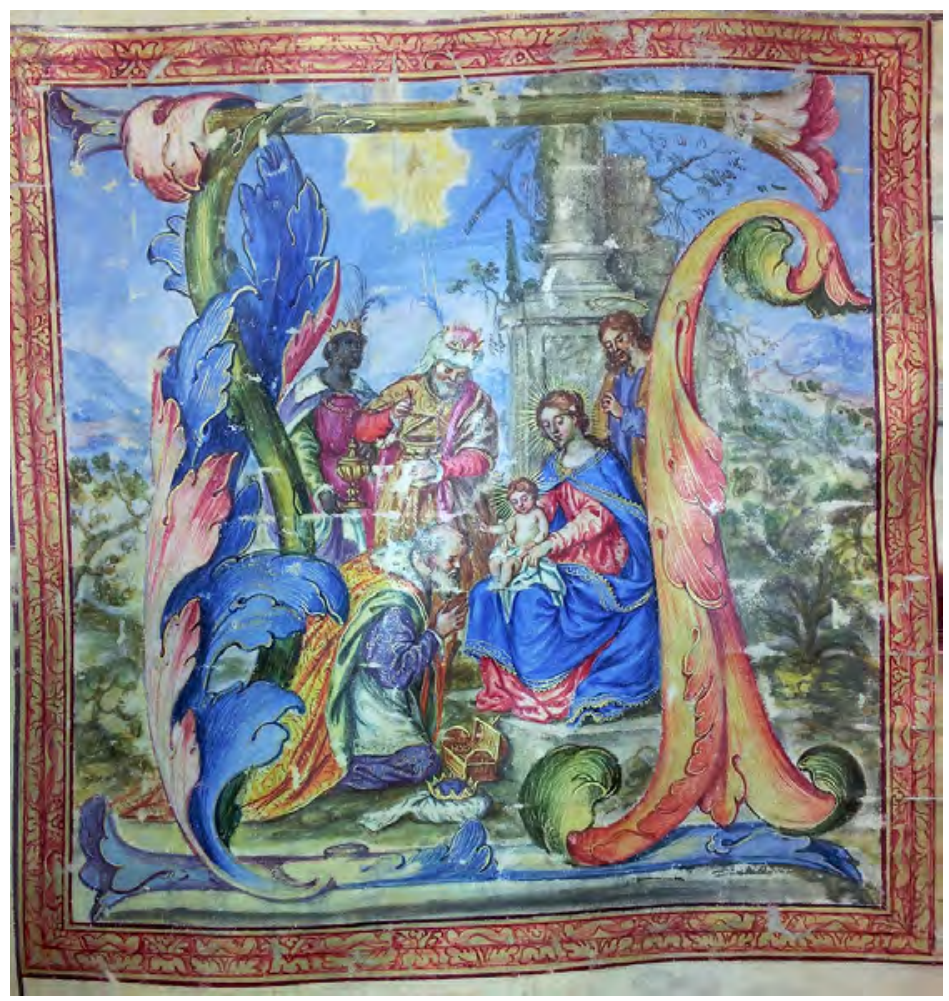

Figura 2. La Epifanía. Salterio de Toledo. Pedro de Obregón, 1654.

Biblioteca Capitular de Toledo.

fol. 61v; la Entrada en Jerusalén, fol. 81v; Madona con Niño, fol. 100r; y Santo Entierro, fol. 125r); Ms. Cantoral 12.1B (David con la cabeza de Goliat, fol. 4r; la Visitación, fol. 21v; la Epifanía, fol. 40v; la Huida a Egipto, fol. 52r; la Última Cena, fol. 63v; la Entrada en Jerusalén, fol. 83v; Madona con Niño, fol. 102r; el Santo Entierro, fol. 127r; y la Inmaculada, fol. 225r); Ms. Cantoral 12.2A (Ecce Homo, fol. 3r); Ms. Cantoral 12.2B (Ecce Homo, fol. 3r); Ms. Cantoral 12.3A (La Imposición de la casulla a san Ildefonso, fol. 6r; Pentecostés, fol. 47v; la Crucifixión, fol. 71r; y la lanzada de Longinos, fol. 93r) ${ }^{19}$.

Pedro de Obregón mantuvo una composición monumental, elaborada bajo un correcto dibujo y un brillante uso de la luz y del color. Ajeno a la dinámica

19 No hemos podido comprobar la relación de viñetas realizadas en el Ms. Cantoral 12.3B por encontrarse en proceso de restauración. 


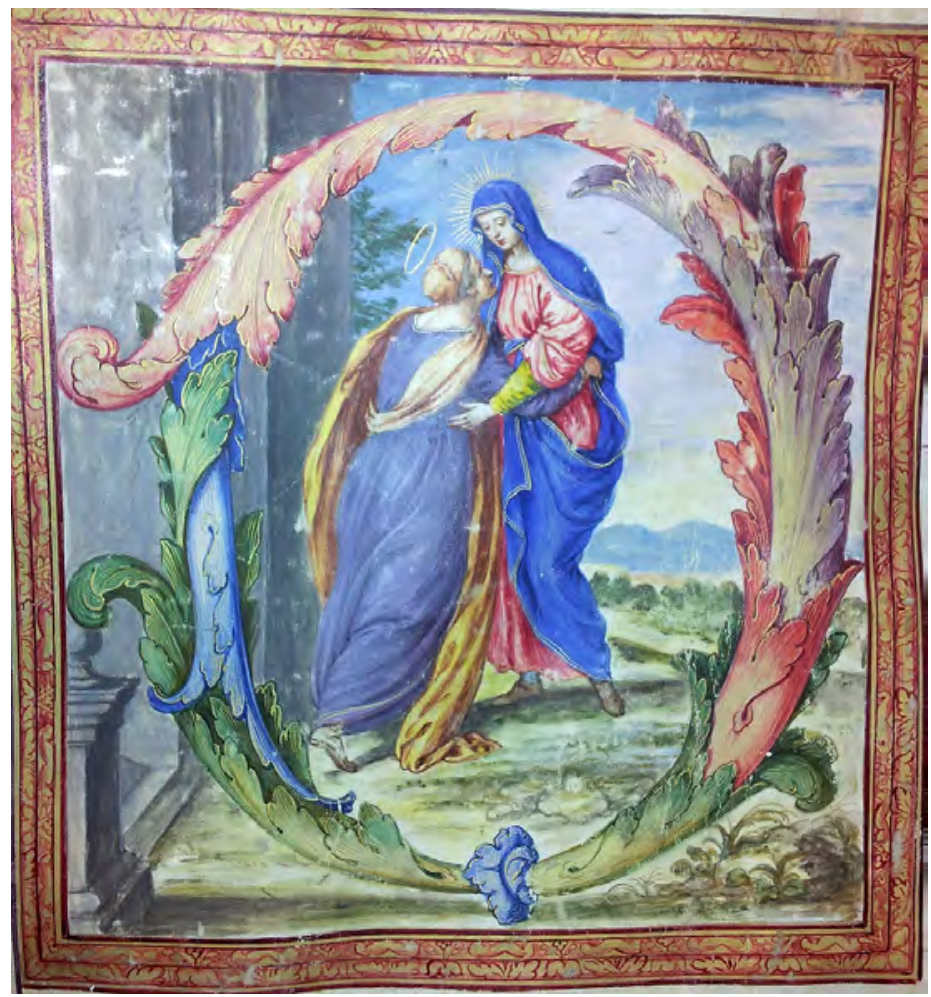

Figura 3. La Visitación. Salterio de Toledo. Pedro de Obregón, 1654.

Biblioteca Capitular de Toledo.

barroca naturalista, su obra en miniatura lo conecta con las composiciones serenas y elegantes de la última etapa de Alonso Cano, en el que también se producen esbeltas composiciones de diagonales y una delicadeza casi poética en los referentes iconográficos de temática religiosa. Partidario de las formas idealizadas, sin perder el dogmático «decoro» contrarreformista, se alejó de los modelos realistas, como observamos en la composición seleccionada para la escena de La Visitación (fig. 3).

El balance optimista ante el uso del color es ya el único recurso de suntuosidad al que se vincula la obra miniada, pues ha perdido su esmerado desarrollo de decoración marginal y se ha convertido en un pequeño cuadro con capacidad de ser analizado, estudiado y entendido de forma independiente, muy alejado del contexto medieval de códice iluminado (Muntada y Atienza 2003). La escena se organiza de manera clara, con una marcada corporeidad en las representaciones, reduciendo al máximo el número de personajes con la finalidad de facilitar la comprensión semántica de la obra. 


\section{CONCLUSIÓN}

Dos han sido los objetivos principales en el desarrollo de nuestra investigación: el primero pretendía hacer visible la labor artística en torno a los códices miniados del siglo XviI conservados en la catedral de Toledo. Como importante centro de creación artística, sus comitentes mantuvieron el encargo de nuevos códices manufacturados a pesar del amplio desarrollo de las técnicas de impresión. El simbolismo de suntuosidad y distinción intrínseco en la obra preparada, copiada e iluminada condujo a una pervivencia de los manuscritos miniados, si bien la centuria del Setecientos denota una progresiva decadencia tanto en el número de ejemplares encargados como en el de profesionales dedicados al oficio, así como en los importantes cambios ornamentales que habían singularizado la decoración de manuscritos a lo largo de los siglos medievales, incluso durante las primeras décadas del Xvi.

En segundo lugar, la aportación documental nos abría la oportunidad de ampliar la información relativa a uno de los pintores espańoles del siglo XVII, cuya escasez de datos biográficos dificulta la atribución y catalogación de sus trabajos. Nos referimos al madrileño Pedro de Obregón, quien ejerció como iluminador para la catedral de Toledo entre los ańos 1653 y 1658. Algunos errores arrastrados de las publicaciones decimonónicas, así como una dudosa hipótesis para su fecha de defunción, han generado una notable controversia a la hora de atribuir alguna de sus obras. Los datos documentales capitulares, así como las inequívocas iluminaciones elaboradas para los cantorales del coro toledano, contribuyen a seguir profundizando en su figura y trayectoria artística. 


\section{BIBLIOGRAFÍA}

Angulo ÍñIguez, D. (1983). La pintura madrileña del segundo tercio del siglo XVII. Madrid: Consejo Superior de Investigaciones Científicas.

CeÁn Bermúdez, J.A. (1800). Diccionario histórico de los más ilustres profesores de las bellas artes en España. Madrid: Imprenta de la Viuda de Ibarra.

Domínguez Bordona, J. (1957). Diccionario de iluminadores españoles. Madrid: Imprenta y Editorial Maestre.

Fernández Collado, A. (1999). La catedral de Toledo en el siglo XVI. Vida, arte y personas. Toledo: Universidad de Castilla-La Mancha.

Fernández Collado, A., Rodríguez González, A. y Castañeda Tordera, I. (2009). Catálogo de impresos de la Biblioteca Capitular. Toledo: Instituto Superior de Estudios Teológicos San Ildefonso.

Gallego, A. (1999). Historia del grabado en España. Madrid: Ediciones Cátedra.

GonzÁlez García, J.L. (2015). Imágenes sagradas y predicación visual en el siglo de oro. Madrid: Akal.

Janini, J. y Gonzálvez, R. (1977). Catálogo de los códices litúrgicos de la Catedral de Toledo. Toledo: Diputación Provincial de Toledo.

Moraleda Moraleda, J. (2018). Los códices iluminados para la catedral de Toledo. El esplendor del arte de la miniatura (s. XVI). Toledo: Cabildo Primado.

Muntada Torrellas, A. (1992). El Misal Rico de Cisneros. Madrid: Real Fundación de Toledo.

Muntada Torrellas, A. y Atienza, J.C. 2003. Cantorales del Monasterio de san Jerónimo de Espaja. Soria: Catedral de Burgo de Osma.

Palacios Blanco, F. (2018). El romano pontifice y la liturgia. Estudio histórico- jurídico del ejercicio y desarrollo de la potestad del papa en materia litúrgica. Toledo: Instituto Teológico san Ildefonso.

Pérez Sánchez, A.E. (1992). Pintura barroca en España, 1600-1750. Madrid: Ediciones Cátedra.

Revenga Domínguez, P. (1999). La Contratación de obras pictóricas en Toledo, 1650-1725. Cuadernos de arte e iconografía 8: 361-370.

Urrea, J. (1994). Pintores del reinado de Felipe IV. Madrid: Museo del Prado, Caja de Ahorros de Navarra. 
